\title{
Metode Linear Predictive Coding (LPC) Pada klasifikasi Hidden Markov Model (HMM) Untuk Kata Arabic pada penutur Indonesia
}

\author{
Ririen Kusumawati
}

\begin{abstract}
Arabic language has a slightly different pronunciation than the Indonesian so to learn it takes a long time. In Arabia itself, there are variants in the pronunciation of the Arabic language or dialect. Dialect is a language, and letters are used by a particular group of people in a clump that makes the difference between the readings even greeting one another. In Indonesia, alone speakers of Indonesia itself have a different dialect to native speakers.
\end{abstract}

This study was analyzed of Arabic writing suitability by Indonesian speakers using Linear Predictive Coding extraction techniques. The text produces different patterns of speech. This also happens if the text is spoken by a speaker who is not the mother tongue of the speakers. The data training in this study is using the Arabic speaker sound. The feature extraction is classified using Hidden Markov Model.

In the classification, using Hidden Markov Model, voice signal is analyzed and searched the maximum possible value that can be recognized. The modeling results obtained parameters are used to compare with the sound of Arabic speakers. From the test results' Classification, Hidden Markov Models with Linear Predictive Coding extraction average accuracy of $\mathbf{7 8 . 6 \%}$ for test data sampling frequency of $8,000 \mathrm{~Hz}, 80.2 \%$ for test data sampling frequency of $22050 \mathrm{~Hz}, 79 \%$ for frequencies sampling test data at $44100 \mathrm{~Hz}$..

Index Terms-Indonesian dialect, Hidden Markov Model, Linear Predictive Coding.

\section{PENDAhUluan}

Bahasa Arab merupakan bahasa yang banyak dipelajari oleh umat muslim di seluruh dunia karena kitab suci Al-Quran ditulis menggunakan bahasa arab. Bahasa Arab formal atau biasa disebut Bahasa Arab klasik adalah Bahasa Arab yang tertulis di Al-Quran dan merupakan standar tatabahasa Arab. Bahasa Arab klasik ini digunakan untuk mempelajari kitab-kitab dan dipelajari di sekolah-sekolah muslim di seluruh dunia. Bahasa ini lebih banyak digunakan untuk penulisan daripada percakapan sehari-hari.

Ririen Kusumawati is with the Infornatic Engineering Departement of UIN Maliki, Malang, Indonesia (email ri2n.kusumawati@gmail.com).
Bahasa Arab, seperti bahasa lainnya juga memiliki beberapa dialek. Dialek ini dapat mengakibatkan kesulitan untuk memahami meskipun diucapkan dalam bahasa yang sama. Bahasa Indonesia banyak sekali menyerap kata dari Bahasa Arab, sama banyaknya seperti menyerap kata dari Bahasa Belanda. Ada kata yang diserap sama seperti aslinya. Ada yang pengucapan dan ejaannya berubah namun artinya tetap sama. Kata serapan yang mirip dengan aslinya misalnya adalah abad, abadi, daftar, nafas, mukmin. Ada juga beberapak kata yang dalam pengucapan dan ejaannya berubah dan mempunyai arti yang sama misalnya adalah "derajat" dari kata darajah, "resmi" dari kata rasmiyyun.

Pada dasarnya, ada dua jenis bahasa arab yaitu bahasa arab klasik dan modern. Bahasa arab klasik adalah bahasa arab yang digunakan di Al-Quran dan digunakan pada abad ke-7 hingga ke-9. Bbahasa arab modern adalah bahasa arab yang lebih santai dibanding bahasa arab klasik. Bahasa arab klasik lebih puitis dan 'kuno', sedangkan bahasa arab modern banyak menyerap katakata asing. Sama seperti bahasa Indonesia klasik yang tercantum dalam buku-buku sastra. Bahasa Indonesia modern seperti sekarang lebih santai dan banyak menyerap kata-kata asing. Namun, tidak ada negara yang menggunakan bahasa arab klasik maupun modern. Di setiap negara, mereka memiliki dialek tersendiri, walaupun mereka mempelajari bahasa arab modern sebagai bahasa formal mereka.

Dialek adalah varian-varian sebuah bahasa yang sama. Varian-varian ini berbeda satu sama lain, tetapi masih banyak menunjukkan kemiripan satu sama lain sehingga belum pantas disebut bahasa-bahasa yang berbeda. Biasanya pemberian dialek adalah berdasarkan geografi, namun bisa berdasarkan faktor lain, misalkan faktor sosial. Sebuah dialek dibedakan berdasarkan kosa kata, tata bahasa, dan pengucapan.

Perkembangan agama Islam sangat pesat di seluruh dunia. Perkembangan agama islam ini mengakibatkan sangat beragamnya dialek bahasa arab yang bukan merupakan bahasa ibu pada setiap daerah masing masing, demikian juga dengan masyarakat Indonesia. Masyarakat Indonesia mempunyai dialek sendiri dalam pengucapan bahasa arab. Perkembangan teknologi komputer pada pengenalan ucapan saat ini membantu manusia untuk memeriksa kesesuaian dengan 
pengucapan bahasa arab dengan penutur Indonesia degan penutur aslinya. Pada pengenalan ucapan, lebih dititik-beratkan pada ekstraksi dari beberapa bagian informasi pesan yang di dalamnya terdapat teks yang diucapkan dalam bentuk lisan. Teks ini mengandung unit-unit linguistik terkecil yang disebut sebagai fonem yang dikenali melalui sinyal suara.

Sinyal suara manusia mempunyai tingkat variabilitas yang sangat tinggi. Sinyal suara yang dalam pengucapannya mengucapkan teks yang berbeda-beda, menghasilkan pola ucapan yang berbeda-beda pula. Hal ini juga terjadi jika pengucapan teks suatu bahasa diucapkan oleh orang yang bukan merupakan bahasa ibu orang tersebut. Misalnya teks kata arab diucapkan oleh orang Indonesia. Bahasa Arab juga memiliki karakteristik sendiri maka beberapa fitur pengolah suara mungkin lebih cocok untuk Bahasa Arab dari yang lain. Dalam penelitian ini, fitur teknik ekstraksi Linear Predictive Coding (LPC) dieksplorasi untuk mendapatkan nilai kesesuaian pada penutur Indonesia terhadap penutur aslinya.

Pada penelitian ini, dilakukan untuk mendapatkan tingkat kesesuaian metode yang diterapkan pada masukan sinyal suara pengucapan kata arabic pada penutur Indonesia. Selanjutnya, fitur yang telah diekstraksi, diklasifikasi menggunakan Hidden Markov Model (HMM).

\section{TINJAUAN PUSTAKA}

\subsection{Ekstraksi Ciri (Feature Extraction)}

Ekstraksi ciri suara adalah untuk mengubah gelombang suara menjadi beberapa tipe representasi parametrik yang dapat diproses. Ada banyak cara untuk merepresentasikan suara secara parametris sehingga dapat diproses lebih lanjut. Salah Satunya adalah menggunakan Linier Predictive Coding (LPC).

Metode LPC diturunkan dari ide dasar bahwa contoh sinyal ucapan pada saat ke $\mathrm{n}, s(n)$, dapat didekati sebagai kombinasi linier dari sejumlah $p$ contoh ucapan sebelumnya [9], yang dapat dinotasikan sebagai berikut:

$$
\begin{gathered}
\widehat{s}_{n} \approx a_{1} s(n-1)+a_{2} s(n-2)+\ldots+a_{i} s(n-i) \\
\widehat{s}_{n}=\sum_{i=1}^{p} a_{i} s_{n-i}
\end{gathered}
$$

Sinyal ucapan pada contoh ke-n, $s(n)$ dapat didekati oleh beberapa buah contoh sebelumnya dengan bantuan koefisien prediksi $a i$, keofisien a1, a2, .., ai diasumsikan sebagai konstanta dalam blok analisis sinyal ucapan. Nilai estimasi ai merupakan hasil terbaik jika jumlah kuadrat kesalahan antara sinyal sebenarnya sn dan sinyal perkiraan $s n$ minimum. Tahap-tahap yang dilakukan adalah sebagai berikut [15]:

Pre-emphasis

Pre-emphasis adalah tahap pertama dari LPC yang memfilter sinyal suara masukan. sinyal suara frekuensi tinggi dilemahkan sehingga sinyal lebih tahan terhadap efek presisi atau pergeseran. Sistem digital yang digunakan oleh fungsi pre-emphasis adalah fixed atau slowly adaptive.

Frame Blocking
Sinyal ucapan hasil pre-emphasis, s(n), seperti yang terlihat pada gambar 1, kemudian di-blok ke dalam frame-frame sebanyak N sampel. Frame-frame yang saling berhubungan dipisahkan oleh $\mathrm{M}$ sample.

\section{Windowing}

Langkah selanjutnya adalah pemberian jendela (windowing) pada tiap tiap frame. Windowing memiliki tujuan untuk meminimalisasi diskontinuitas sinyal pada awal dan akhir masing-masing frame.

\section{Analisis Autokorelasi}

Masing-masing frame dari sinyal yang telah dilakukan proses windowing, dilakukan autokorelasi. Pada rumus 1. Nilai $\mathrm{p}$ adalah nilai tertinggi pada autokorelasi. Nilai $\mathrm{p}$ digunakan pada langkah berikutnya yaitu analisis LPC.

$$
r_{\ell}(m)=\sum_{n=0}^{N-1-m} \overline{x_{\ell}}(n) \overline{x_{\ell}}(n+m), \text { dengan } m=0,1, \ldots, p .
$$

\section{Analisis LPC}

Analisis LPC merupakan proses untuk mengubah masing-masing frame dari autokorelasi $p+1$ ke dalam bentuk parameter LPC. Parameter tersebut dapat terdiri dari koefisien LPC, koefisien refleksi, koefisien log area ratio, koefisien cepstral, atau transformasi ke bentuk set yang diinginkan.

\subsection{Hidden Markov Model (HMM)}

Hidden Markov Model (HMM) adalah model statistik dari sebuah sistem yang diasumsikan sebuah proses Markov dengan parameter yang tak diketahui, dan tantangannya adalah menentukan parameterparameter tersembunyi (hidden) dari parameterparameter yang dapat diamati. Pada model Markov umum, keadaannya-nya dapat langsung dapat diamati, oleh karena itu probabilitas transisi keadaan menjadi satu-satunya parameter. Di dalam HMM, keadaan-nya tidak dapat diamati secara langsung, akan tetapi yang dapat diamati adalah variabel-variabel yang terpengaruh oleh keadaan. [10]

\section{Metodologi Penelitian}

\subsection{Pengumpulan Data.}

Pengumpulan data yang terkait adalah sebagai berikut:

a. Data uji coba dilakukan oleh penutur asli Indonesia sebanyak 3000 contoh suara. 150 contoh suara ini adalah sebanyak 5 orang penutur asli Indonesia yang tidak terlalu fasih berbahasa arab dan 5 orang penutur asli Indonesia yang lebih fasih berbahasa arab dari 5 penutur sebelumnya, setiap penutur mengucapkan 15 kata dalam bahasa arab dan dilakukan pengulangan sebanyak 20 kali pengucapan.

b. Data Uji menggunakan direkam menggunakan mikrophone pada laptop dengan frekuensi sampling $8000 \mathrm{~Hz}, 22050 \mathrm{~Hz}, 44100 \mathrm{~Hz} 16$ bit PCM Mono dengan format suara .wav. Data uji didapat dengan cara merekam setiap kata dari setiap penutur 
sebanyak 20 ucapan dan direkam pada frekuensi sampling $44100 \mathrm{~Hz}$. Data ucapan penutur ini disimpan dalam bentuk file sebanyak 20 file dengan format .wav untuk setiap penutur. Sehingga untuk frekuensi sampling $44100 \mathrm{~Hz}$ didapat data ucapan berbentuk file sebanyak $10 \times 20=200$ file.

c. Data uji dengan frekuensi sampling $22050 \mathrm{~Hz}$ didapat dari mengkonversi data file dengan frekuensi sampling $44100 \mathrm{~Hz}$ menjadi frekuensi sampling $22050 \mathrm{~Hz}$ dan disimpan dalam bentuk file. Data uji yang didapat dari hasil konversi ini juga sebanyak 200 file

d. Data uji dengan frekuensi sampling $8000 \mathrm{~Hz}$ didapat dari mengkonversi data file dengan frekuensi sampling $22050 \mathrm{~Hz}$ menjadi frekuensi sampling $8000 \mathrm{~Hz}$ dan disimpan dalam bentuk file. Data uji yang didapat dari hasil konversi ini juga sebanyak 200 file.

e. Jumlah keseluruan data uji adalah sebanyak $200 \times 3$ data uji $=600$ data uji untuk satu kata yang diucapkan oleh semua penutur.

f. Jadi data uji untuk 15 kata yang diucapkan oleh kesemua penutur adalam sebanyak 15 × 600 data uji $=9000$ data uji.

\subsection{Pengumpulan data yang digunakan untuk training.}

Pengumpulan data yang digunakan untuk data training adalah suara kata dalam bahasa arab yang diucapkan oleh penutur asli penutur arab. File suara yang didapat didapat dari youtube pada pembelajaran bahasa arab oleh instruktur penutur arab. Data training sebanyak 90.

\subsection{Pengujian dan evaluasi}

Pengujian dilakukan menggunakan kata bahasa arab sebanyak 15 kata dalam bentuk file wav dan diucapkan oleh 6 penutur Indonesia. Setiap penutur melakukan pengulangan kata yang sama sebanyak 20 kali. Ucapan yang terbanyak yang dikenali oleh sistem dianggap sebagai hasil akhir. Perekaman ucapan penutur indonesia menggukan mikrophone yang terdapat dalam komputer Netbook Aspire One Intel Celeron 1,6 GHz.

\section{HASIL DAN PEMBAHASAN}

\subsection{Pengujian Akurasi}

Pengujian ini untuk mengetahui kemampuan sistem untuk mengenali 2700 kata bahasa arab dalm bentuk file yang telah didapat dan direkam dari 6 penutur indonesia. Nilai parameter standar yang dimasukan dalam sistem yang diberlakukan untuk semua data uji adalah sebagai berikut:

pre-emphasis: 0.95 ,

jumlah filterbank: 20,

jumlah koefisien LPC: 20.

Jumlah state HMM : 10

Nilai parameter yang ditentukan merupakan hasil penelitian awal yang menunjukkan nilai pengenalan yang optimum dan lebih baik. Pengujian pada sistem ini menggunakan bantuan perangkat keras berupa satu unit laptop Aspire One Intel Celeron 1,6 GHz. Laptop ini dilengkapi dengan Microphone Realtek High Definition untuk merekam data uji, serta perangkat lunak Matlab
R10 dan perangkat lunak perekam data suara yaitu Audacity.

Pengujian yang dilakukan dititik beratkan pada tingkat akurasi dalam mengenali setiap data uji. Pengujian tingkat akurasi ini untuk mengetahui tingkat akurasi klasifikasi hidden markov model untuk mengenali ucapan dalam satu frekuensi sampling, serta perbedaan dalam mengenali ucapan dalam tiga frekuensi sampling yang berbeda.

Kata yang diucapkan sebagai data uji dipilih secara acak yang dipergunakan dalam komunikasi sehari hari. Dalam pengambilan data, kata tersebut ditulis dalam huruf latin menggunakan pedoman transliterasi dari kementrian agama Republik Indonesia dan penutur mengucapkannya sesuai dengan kemampuan masingmasing. Tidak ada kekhususan dalam pemilihan kata bahasa arab. Kata-kata tersebut adalah sebagai berikut: Alhamdulillah;Bikhair;Ismi;Syukran;Afwan;Ahsanta;N a'am;La;Shahih;Shadaqta;Baarakallah;Syafakallah;Ha fizhanallah;Hadaanallah;Tafadhdhal. Dari hasil pengujian didapat \% Akurasi seperti yang ditunjukkan pada gambar 2 pada frekuensi sampling $8000 \mathrm{~Hz}$, gambar 3 pada frekuensi sampling $22050 \mathrm{~Hz}$, dan gambar 4 pada frekuensi sampling $44100 \mathrm{~Hz}$.

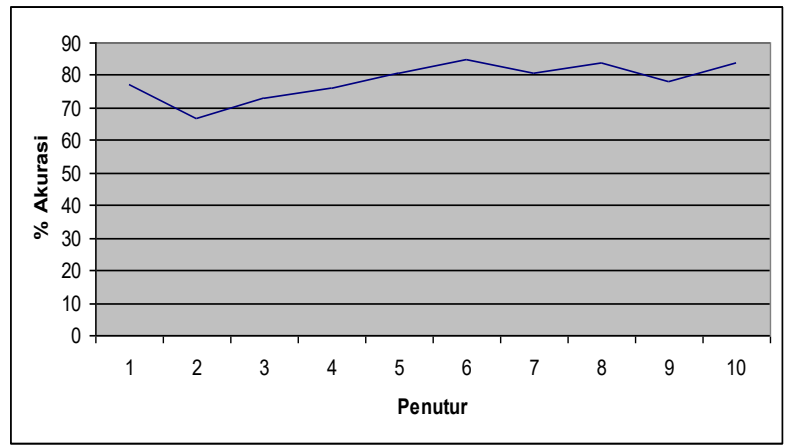

Gambar 1 Grafik \% Akurasi pada frekuensi sampling 8000Hz.

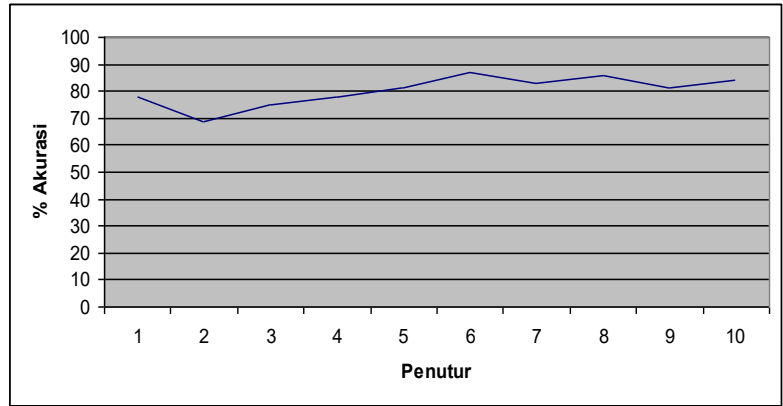

Gambar 2 Grafik \% Akurasi pada frekuensi sampling $22050 \mathrm{~Hz}$

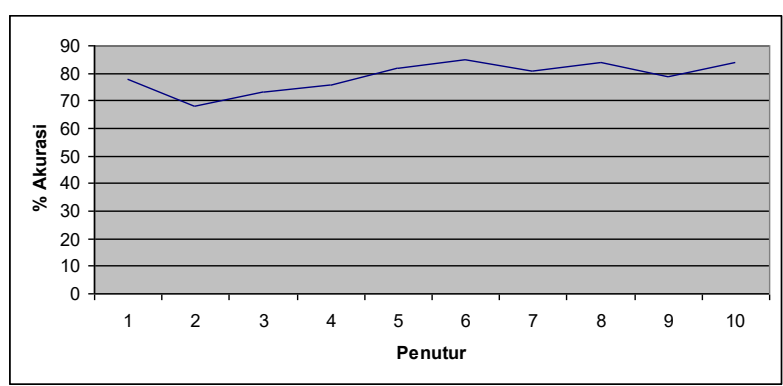

Gambar 3 Grafik \% Akurasi pada frekuensi sampling $44100 \mathrm{~Hz}$ 
Kefasihan dalam membaca tulisan kata arab juga mempengaruhi keakurasian sistem dalam mengenali ucapan. Hal ini dapat dilihat pada gambar 2, 3, dan 4 pada penutur 1 sampai dengan 5 yang mempunyai \% Akurasi dibawah nilai 80. Frekuensi sampling yang semakin besar juga mengakibatkan penurunan tingkat akurasi.

\section{KESIMPULAN}

Dari hasil pengujian disimpulkan sebagai berikut :

1. Sistem menghasilkan nilai akurasi rata-rata sebesar 78,6\% untuk frekuensi sampling data uji sebesar $8000 \mathrm{~Hz}, 80,2 \%$ untuk frekuensi sampling data uji sebesar $22050 \mathrm{~Hz}, 79 \%$ untuk frekuensi sampling data uji sebesar $44100 \mathrm{~Hz}$.

2. Penutur yang fasih mengucapkan bahasa arab mempunyai tingkat keakurasian yang lebih tinggi daripada orang yang bisa bahasa arab tetapi belum fasih. Hal ini disebabkan karena dalam mengucapkan kata arab, penutur indonesia berusaha untuk mengucapkan bahasa arab sesuai dengan asli nya.

3. Dialek juga mempengaruhi tingkat keakurasian sistem dalam mengenali ucapan. Hal ini dibandingkan dengan penelitian sebelumnya dengan data uji berasal dari dialek arab.

\section{DAFTAR PUSTAKA}

[1] Abriyono, Agus Harjoko, " Pengenalan Ucapan Suku Kata Bahasa Lisan Menggunakan Ciri LPC, MFCC, dan JST”, IJCCS, Vol.6, No.2, July 2012, pp. $23 \sim 34$.

[2] Alcaraz Meseguer, Noelia, 2009, "Speech Analysis for Automatic Speech Recognition", Norwegian University of Science and Technology Department of Electronics and Telecommunications, 2009.

[3] Aria, Muhammad, "Sistem Pengenalan Kata Bahasa Indonesia Berbasis LabView untuk Pengendalian Peralatan Ruang Perkuliahan", Universitas Komputer Indonesia, 2013.

[4] Ashikin Binti Norzain, Norul, "Security System Using Biometric Technology: Voice Recognition", Faculty of Electrical Engineering, Universiti Teknologi Malaysia, 2014.

[5] Elkourd, Amer M., "Arabic Isolated Word Speaker Dependent Recognition System", Islamic University, Gaza, Palestine Deanery of Higher Studies Faculty of Engineering Computer Engineering Department, 2014.
[6] Elminir, Hamdy K. , Mohamed Abu ElSoud, L. M. Abou El-Maged," Evaluation of Different Feature Extraction Techniques for Continuous Speech Recognition", International Journal of Information and Communication Technology Research, 2012.

[7] Holmes, J. \& Holmes, W. , "Speech Synthesis and Recognition", 2th ed., Tailor \& Francis, London, 2001.

[8] Ibrahim, Noor Jamaliah Binti, “Automated Tajweed Checking Rules Engine For Quranic Verse Recitation", Faculty Of Computer Science And Information Technology University Of Malaya Kuala Lumpur, 2010.

[9] J. SANGEETHA et al, " Efficient Continuous Speech Recognition Approaches for Dravidian Languages”, DOI 10.5013/IJSSST.a.15.02.03, 2015.

[10] Rabiner, L. and Juang, B. H. (1993). Fundamentals of Speech Recognition. Englewood Cliffs, N.J.: Prentice Hall. pp.42-481.

[11]Rozaq, Ahmad, dkk, "Identifikasi Ciri Musik Dengan Menggunakan Mel-Frekuensi Cepstral Coefficien (MFCC)", Politeknik Elektronika Negeri Surabaya, 2010.

[12] Shah, Nazaruddin bin MD, "Voice Activation Switch", Fakulti Kejuruteraan Elektronik dan Kejuruteraan Komputer Universiti Teknikal Malaysia Melaka, 2007.

[13] Sijabat, Davit Wasty, "Simulasi Pengenalan Chord Terisolasi Berbasiskan Speaker Dependent Dengan Metode Hidden Markov Model", Fakultas Teknik Universitas Indonesia, 2009.

[14] S. Y. Mark Gales, "The Application of Hidden Markov Models in Speech Recognition" dalam Foundations and Trends in Signal Processing, 2007.

[15] Taufik Adnan Amal, "Rekonstruksi Sejarah AlQur'an", Cet. I; Penerbit Forum Kajian Budaya dan Agama, Yogyakarta. h. 151, 2001.

[16] Utami, Sri, " Sistem Pengendalian Dan Monitoring Peralatan Rumah Tangga Jarak Jauh Dengan Metode Pengenalan Wicara", Politeknik Negeri Bandung, 2012. 